\title{
Diabetes and periodontitis: multidisciplinary management
}

\author{
Harinder S. Sandhu* and Jaffer A \\ Division of Periodontics, Schulich School of Medicine and Dentistry, London, Canada
}

\begin{abstract}
Diabetes has reached epidemic levels in North America and continues to rise in prevalence, generating a significant financial burden on society. The strong link between type 2 diabetes and periodontitis provides a sound basis for dental professionals to screen for and help manage diabetic patients. Literature from journals of both medicine and dentistry was included to provide a comprehensive examination of the bi-directional relationship between diabetes and periodontitis. This review highlights the necessity for multidisciplinary management of patients suffering from both disease processes, and the benefits of how treatment of one can positively impact the other. Additional analysis of the precise effect of hyperglycemia on the severity and progression of periodontal disease should be conducted to gain further insight into the relationship between the two diseases. It is incumbent on oral health care providers to become a partner in managing patients with periodontitis and type-2 diabetes.
\end{abstract}

\begin{abstract}
Abbreviations: AGE: advanced glycated end product; BOP: bleeding on probing; CDC: center for disease control; DM: diabetes mellitus; HbAlc: hemoglobin Alc; LPS: lipopolysaccharide; MMP: matrix metalloproteinases; NET: neutrophil extracellular trap; PISA: periodontal inflamed surface area; PD: probing depths; PMN: polymorphonuclear lymphocyte; RAGE: receptor of advanced glycation end product; RANKL: receptor activator of nuclear factor kappa-b ligand; ROS: reactive oxygen species; T2DM: type 2 diabetes mellitus; TNFalpha: tumor necrosis factor-alpha
\end{abstract}

\section{Introduction}

Diabetes is a progressive, chronic disease with numerous pathophysiological abnormalities resulting in sustained hyperglycemia. It greatly increases the risk of micro- and macro-vascular diseases and, when left uncontrolled, is a major cause of mortality [1]. Incidence of diabetes in Canada and USA is reported to be $9.3 \%$ and $8.9 \%$ respectively, not including the substantial number of individuals who may also be undiagnosed prediabetics $[2,3]$. Once a definitive diagnosis of Type II diabetes is established, physicians make a determination to control the glycemic level based on a number of factors including comorbidities affecting the cardiac, renal, ophthalmic and other physiological systems [4] The relationship between diabetes and periodontitis is not as clearly understood. The premise of this article is to explore the relationship between the systemic control of diabetes mellitus (DM) and the progression of periodontal disease, as well as to evaluate the need for stricter diabetic control guidelines for optimized periodontal health. Based on current literature, diabetes mellitus and periodontitis have been linked via the immune system [5,6], and gaining a clearer picture of how each can have a significant impact on the other holds great value.

Diabetes mellitus is classified as insulin-dependent (Type 1) or non-insulin-dependent (Type 2) subtypes. It is characterized by elevated blood glucose levels [7]. Systemic implications of DM due to prolonged hyperglycemia include damage to blood vessels and impaired immune function [6]. Diagnostically, the World Health Organization outlines the following criteria for DM: fasting plasma glucose levels $\geq 7.0 \mathrm{mmol} / \mathrm{L}$; plasma glucose $\geq 11.1 \mathrm{mmol} / \mathrm{L}$ two hours after administration of $75 \mathrm{~g}$ oral glycemic load; and glycated hemoglobin (HbAlc) $\geq 6.5 \%$ [8]. Periodontitis involves the progressive destruction of the attachment apparatus of involved teeth due to an exaggerated inflammatory response $[9,10]$. This includes loss of alveolar bone, apical migration of junctional and pocket epithelium and eventual pathological exfoliation of periodontally compromised teeth $[9,10]$. The commonalities present in the pathogenesis for both diseases serve as a starting point in understanding how they influence each other, and why it is important for dentists to work with physicians to set stricter $\mathrm{HbA1c}$ targets to facilitate periodontal health.

\section{Effect of diabetes on neutrophil function}

As mentioned above, DM significantly affects cells of the immune system. Neutrophils are the most abundant type of white blood cell and are integral in mounting the initial response to invading organisms and their by-products [11,12]. A prolonged state of hyperglycemia has adverse effects on the function of these cells and therefore hinders the body's ability to initiate an appropriate immune response against pathogenic microorganisms. The impaired neutrophil function, which presents a number of ways, is the source of increased susceptibility to infection in DM patients. Neutrophil dysfunction in these patients includes decreased bacteriocidal activity, impaired phagocytosis and decreased release of lysozomal enzymes [13,15].

A specific biological implication of prolonged hyperglycemia that affects neutrophil function is the formation of advanced glycated end products (AGEs); AGEs are the result of the interaction between

Correspondence to: Dr. Harinder S. Sandhu, Division of Periodontics, Schulich School of Medicine and Dentistry, Western University, 0079 Dental Sciences Building, London, Ontario, Canada, N6A 5C1, Tel: 519-619-1762; Fax: 519-8502316; E-mail: hsandhu@uwo.ca

Key words: diabetes mellitus, glycemic control, neutrophils, periodontitis, patient management

Received: March 15, 2016; Accepted: March 31, 2016; Published: April 05, 2016 
proteins and lipids with glucose or its byproducts $([13,14]$. AGEs are increased in DM patients due to the accumulation of metabolites stemming from the inability of cells to regulate glucose uptake [13]. This increase in AGEs subsequently enhances neutrophil activity and is a key factor for atypical inflammation in DM patients $[13,16]$. This increase in neutrophil activity occurs due to the presence of the receptor for AGEs (RAGE) on neutrophil plasma membrane [13,14]. Monocytes and macrophages have been identified to have AGE receptors as well [17]. The calcium-dependent activation of neutrophils via the AGE-RAGE complex results in abnormal chemotaxis and irregular neutrophil response [14]. Collison et al. [14] revealed that although these neutrophils are hyper-responsive, the ability of these cells to kill ingested bacteria was reduced as a result of the inhibition of reactive oxygen species (ROS).

Sustained hyperglycemia also causes an increase in neutrophil extracellular traps (NETs), which are responsible for containing and killing pathogens $[15,16,18]$. NETs are composed of decondensed chromatin and cytotoxic proteins. NETs are also capable of inducing tissue damage and delaying wound healing $[15,16]$. Increased release of tumour necrosis factor-alpha (TNF-alpha), elevated blood glucose and elevated basal calcium levels in neutrophils are all characteristic of DM and facilitate the production and release of NETs [15]. Lipopolysaccharides (LPS) also promote neutrophils to release NETs; this leads to an increase in concentration of neutrophil elastase, a component of NETs capable of degrading the wound scaffold and delaying healing $[16,18]$. This is especially important in staphylococcusinfected wounds, common in diabetics, due to inability of NETs to effectively kill these microorganisms [15]. Therefore, the inability of NETs to defend against such bacteria and the potential for additional tissue damage further illustrates how DM may affect local tissue damage in the periodontium.

\section{Pathogenesis of periodontitis}

Periodontitis is considered to be a multifactorial, infectious disease. The characteristic feature of chronic periodontitis is inflammation of the tooth-supporting tissues resulting in progressive attachment and bone loss $[19,20]$. The destruction of supporting structures is directly related to inflammatory immune response to supra- and subgingival accumulation of bacterial colonies found in plaque and biofilms [19]. The increased bacterial load and invasion of microorganisms into these supporting structures causes the recruitment of neutrophils to the periodontal tissues $[19,20]$. As bacteria colonize the junctional epithelium and invade the connective tissue, the host immune response is initiated by the release of cytokines interleukin-1, interleukin-6, interleukin-8, TNF-alpha and prostaglandin E2 (PGE2) to attract neutrophils, macrophages and lymphocytes [21]. As these polymorphonuclear leukocytes (PMNs) travel to the site of bacterial accumulation, healthy gingival tissue is destroyed as a by-product of their recruitment; the primary mediators responsible for this are cytokines, matrix metalloproteinases (MMPs) and prostaglandin E2 [21,22]. In a healthy host, the physiological immune response will control the inflammatory process, eliminate the invading microorganisms, allow for the tissues to heal and prevent the disease process from destroying the teeth-supporting structures [19].

However, once the bacterial load overwhelms the host immune system, irreversible destruction of the affected supporting structures occurs $[19,23]$. Bacterial colonies invading the gingival tissues proliferate and change composition, forming a complex biofilm resistant to host defense mechanisms [23]. The main offending bacteria implicated as causative mediators of periodontitis are: $P$. gingivalis, Treponema denticola and Tannerella forsythia. A newer model of pathogenesis describes a more diverse microbial composition of pathogenic bacteria capable of synergistically disrupting the protective biofilm associated with periodontal homeostasis [23]. However, the previously mentioned microbes continue to be central to the progression of the disease. As a natural response to the increased bacterial load of these virulent bacteria, the immune system continues to release MMP and PGE2 and recruit additional PMNs, propagating the destruction of the periodontal attachment apparatus [19]. This causes a shift favoring the destruction of collagen (ex. connective tissue, periodontal ligament) and stimulates osteoclasts to initiate destruction of alveolar bone $[24,25]$. As described above, neutrophil dysfunction is characteristic of diabetic patients and could very plausibly influence the severity of periodontitis.

\section{Relationship between diabetes and periodontitis}

The severity of periodontitis is influenced by a number of risk factors. Sustained hyperglycemia in T2DM is a significant risk factor for periodontitis. Many studies have shown the close, bi-directional relationship between periodontal status and $\mathrm{HbAlc}$ levels. Morita et al. [26] concluded that in patients with $\mathrm{HbAlc}$ of $\geq 6.5 \%$ at baseline, the relative risk of developing a periodontal pocket at 5-year interval reevaluation was 1.17 (post-adjustment for body mass index, smoking incidence, sex, and age).

Saito et al. [27] conducted a retrospective cohort study identifying the increased likelihood of periodontal pocket development in patients with impaired glucose tolerance, a hallmark of T2DM. An increase in pocket formation perpetuates the progression of periodontitis by providing greater surface area for the proliferation of the bacterial biofilm responsible for clinical attachment and bone loss. It also increases periodontal inflamed surface area (PISA), which in turn can provide systemic access to microorganisms and their products [28].

Ayilavarapu et al. [29] reported that patients aged $\geq 45$ years with poorly controlled blood glucose level (indicated by HbAlc $>9 \%$ ) have a greater incidence of severe chronic periodontitis compared to patients without T2DM. Lim et al. [30] investigated the effect of insufficient glycemic control on periodontal disease by measuring the increase in bleeding-on-probing (BOP) percentage and mean percentage of sites with probing depths $(\mathrm{PD}) \geq 5 \mathrm{~mm}$, and found a positive correlation between $\mathrm{HbA} 1 \mathrm{c} \geq 8 \%$ and both elevated $\mathrm{BOP}$ and $\mathrm{PD} \geq 5 \mathrm{~mm}$. This study determined the significance of poor glycemic control with respect to periodontal health. In the majority of studies, patients who suffered from DM but were sufficiently controlled did not exhibit a greater incidence of periodontal disease when compared to healthy individuals.

\section{Periodontal management of diabetic patient}

Non-surgical treatment of periodontitis is geared towards mechanical disruption of the bacterial ecosystem, which is otherwise well protected from the host immune system. Stewart et al. [31] carried out a retrospective controlled trial illustrating that in patients with type 2 diabetes mellitus (T2DM) and chronic periodontitis, mechanical debridement produced a significant decrease in systemic glycated hemoglobin levels compared to a control group receiving no treatment. The treatment group in this case was shown to have a $17.1 \%$ decrease in $\mathrm{HbAlc}$ levels at the 10-month follow-up, compared to $6.7 \%$ in the control group [32]. Teeuw et al. [33] conducted a meta-analysis that stated periodontal treatment of T2DM patients resulted in a decrease in $0.4 \%$ in HBAlc level following treatment. Therefore, regular 
mechanical debridement should be considered even more critical for diabetic patients, as not only must the source of bacteria be removed for periodontal health, the associated lowering of HbAlc levels can benefit systemic health as well.

If patients do not respond to mechanical debridement, antibiotic therapy can be used in conjunction with scaling and root planing. Doxycycline is a commonly administered antibiotic for targeting the offending microorganisms and has been extensively studied in conjunction with scaling and root planing [34]. O'Connell, et al. [35] compared $\mathrm{HbAlc}$ level reductions in groups undergoing mechanical debridement only, and in conjunction with doxycycline. At 3-month reevaluation, the group treated with mechanical debridement had $0.9 \%$ reduction in $\mathrm{HbAlc}$, while the debridement plus antibiotic therapy produced $1.5 \%$ reduction [35]. Due to the increased susceptibility of diabetic patients to periodontitis as well as the added incentive of lowering HbAlc levels and associated co-morbidities, diabetic patients should follow a strict, short-interval recall schedule to maintain periodontal health and promote systemic health.

\section{Glycemic control targets and periodontal stability}

In the past, diabetes has been managed primarily by the patient and the physician. As we begin to understand the oral health complications of diabetes, it is evident that a multidisciplinary approach will be necessary to provide the best possible care to affected patients. Physician-guided glycemic control targets will often mitigate many of these hyperglycemia-related complications, however, periodontitis is often overlooked. It is, therefore, absolutely crucial for managing healthcare providers to work together to individualize glycemic targets on a patient-to-patient basis, based on the status and severity of affecting comorbidities. According to the American Diabetes Association [36], the $\mathrm{HbAlc}$ target for an average patient should be $7.0 \%$. In patients that are otherwise physiologically stable, stricter targets closer to $6.5 \%$ can be employed [36 ]. A less stringent target of 8.0\%, however, is employed for brittle patients whose risk for diabetes-related complications outweighs the benefit of tighter control [36]. In reality, a large number of patients are considered within acceptable range of glycemic control as long as the $\mathrm{HbA1c}$ value is below $8.0 \%[37,38]$. However, at this level, the disruption of the immune system has significant implications for oral health.

Like diabetics, another group of individuals at risk of increased incidence of periodontitis is prediabetics. It is estimated that for every diagnosed T2DM patient, there is an equal number of undiagnosed prediabetics who are at significant risk of becoming diabetic [39]. Approximately $70 \%$ of the North American population visits the dentist at least once per year [40,41], allowing for an excellent opportunity to better screen and manage affected patients. Despite the strong association between periodontitis and elevated HbAlc levels, very few dental offices assess the diabetic risk of patients or measure blood glucose levels. It has been estimated that $93.4 \%$ of dental patients qualify for diabetic screening [42] with simplified diabetic screening tools being made available by the National Diabetes Prevention Program [43] in the United States and the Canadian Diabetes Association [43]. Pharmacies in Canada and USA are also equipped to offer diabetic screening instruments. Despite current prevention efforts, the incidence of diabetes and related medical care costs are estimated to double in five years [44]. It is incumbent on dental professionals to participate in the overall well being of patients, and is high time the dental profession joins the crusade against this insidious and debilitating disease.

\section{Conclusion}

Dental management of diabetic patients is a complex, systematic process, requiring consideration of multiple risk factors and physiological responses. Although the effect of DM on periodontitis, and vice versa, provides substantial evidence of a bi-directional relationship, more in-depth studies exploring the effect of elevated $\mathrm{HbAlc}$ on periodontitis are required to fully understand the precise impact hyperglycemia has on the severity and progression of periodontal disease. It is absolutely critical for patients suffering from both diseases to effectively regulate their hyperglycemia, reducing the risk of irreversible periodontal destruction. This, along with the inherent systemic benefits of lowering $\mathrm{HbAlc}$ levels, further provides motivation to implement tighter control and more individualized glycemic targets. In conclusion, it is becoming increasingly evident that a multi-disciplinary approach to treatment is the best path to successfully managing systemic and oral health.

\section{Competing interest}

The authors declare that they have no competing interests.

\section{References}

1. American Diabetes Association (2010) Diagnosis and classification of diabetes mellitus. Diabetes Care 33 Suppl 1: S62-69. [Crossref]

2. Canadian Diabetes Association (2015) Diabetes in Canada.

3. National Center for Chronic Disease Prevention and Health Promotion (2014) National Diabetes Statistics Report.

4. Brownlee M (2001) Biochemistry and molecular cell biology of diabetic complications Nature 414: 813-820. [Crossref]

5. Iacopino AM (2001) Periodontitis and diabetes interrelationships: role of inflammation. Ann Periodontol 6: 125-137. [Crossref]

6. Nassar H, Kantarci A, van Dyke TE (2007) Diabetic periodontitis: a model for activated innate immunity and impaired resolution of inflammation. Periodontol 2000 43: 233244. [Crossref]

7. Canadian Diabetes Association Clinical Practice Guidelines Expert Committee, Goldenberg R, Punthakee Z (2013) Definition, classification and diagnosis of diabetes, prediabetes and metabolic syndrome. Can J Diabetes 37 Suppl 1: S8-11. [Crossref]

8. Alberti KG, Zimmet PZ (1998) Definition, diagnosis and classification of diabetes mellitus and its complications. Part 1: diagnosis and classification of diabetes mellitus provisional report of a WHO consultation. Diabet Med 15: 539-553. [Crossref]

9. Roberts H, Ling M, Insall, R., et al., 2015) Impaired neutrophil directional chemotactic accuracy in chronic periodontitis patients. J Clin Periodontol 42: 1-11. [Crossref]

10. Landzberg M, Doering H, Aboodi GM, Tenenbaum HC, Glogauer M (2015) Quantifying oral inflammatory load: oral neutrophil counts in periodontal health and disease. J Periodontal Res 50: 330-336. [Crossref]

11. Kolaczkowska E, Kubes P (2013) Neutrophil recruitment and function in health and inflammation. Nat Rev Immunol 13: 159-175. [Crossref]

12. Burg ND, Pillinger MH (2001) The neutrophil: function and regulation in innate and humoral immunity. Clin Immunol 99: 7-17. [Crossref]

13. Alba-Loureiro TC Munhoz CD, Martins JO, Cerchiaro GA, Scavone C, et al. (2007) Neutrophil function and metabolism in individuals with diabetes mellitus. Braz J Med Biol Res 40: 1037-1044. [Crossref]

14. Collison KS, Parhar RS, Saleh SS, Meyer BF, Kwaasi AA, et al. (2002) RAGEmediated neutrophil dysfunction is evoked by advanced glycation end products (AGEs). J Leukoc Biol 71: 433-444. [Crossref]

15. Wong SL, Demers M, Martinod K, Gallant M, Wang Y, et al. (2015) Diabetes primes neutrophils to undergo NETosis, which impairs wound healing. Nat Med 21: 815-819. [Crossref]

16. Sefil F, Ulutas KT, Dokuyucu R, Sumbul AT, Yengil E, et al. (2014) Investigation of neutrophil lymphocyte ratio and blood glucose regulation in patients with type 2 diabetes mellitus. $J$ Int Med Res 42: 581-88. [Crossref] 
17. Vlassara H (2001) The AGE-receptor in the pathogenesis of diabetic complications. Diabetes Metab Res Rev 17: 436-443. [Crossref]

18. Nauseef WM (2014) Proteases, neutrophils, and periodontitis: the NET effect. $J$ Clin Invest 124: 4237-4239. [Crossref]

19. Schenkein HA(2006) Host responses in maintaining periodontal health and determining periodontal disease. Periodontol 2000 40: 77-93. [Crossref]

20. Johnstone AM, Koh A, Goldberg MB, Glogauer M (2007) A hyperactive neutrophil phenotype in patients with refractory periodontitis. J Periodontol 78: 1788-1794. [Crossref]

21. Ling MR, Chapple IL, Matthews JB (2015) Peripheral blood neutrophil cytokine hyperreactivity in chronic periodontitis. Innate Immun 21: 714-725. [Crossref]

22. Pacios S, Kang J, Galicia J, Gluck K, Patel H, Ovaydi-Mandel A, et al. (2012) Diabetes aggravates periodontitis by limiting repair through enhanced inflammation. FASEB $J$ 26:1423-30. [Crossref]

23. Hajishengallis G1 (2015) Periodontitis: from microbial immune subversion to systemic inflammation. Nat Rev Immunol 15: 30-44. [Crossref]

24. Taubman MA, Kawai T, Han X (2007) The new concept of periodontal disease pathogenesis requires new and novel therapeutic strategies. J Clin Periodontol 34: $367-$ 9. [Crossref]

25. Sorsa T, Tjäderhane L, Konttinen YT, Lauhio A, Salo T, et al. (2006) Matrix metalloproteinases: contribution to pathogenesis, diagnosis and treatment of periodontal inflammation. Ann Med 38: 306-321. [Crossref]

26. Morita I, Inagaki K, Nakamura F, Noguchi T, Matsubara T, et al. (2012) Relationship between periodontal status and levels of glycated hemoglobin. J Dent Res 91: 161-166. [Crossref]

27. Saito T, Shimazaki Y, Kiyohara Y, Kato I, Kubo M, et al. (2004) The severity of periodontal disease is associated with the development of glucose intolerance in nondiabetics: the Hisayama study. J Dent Res 83: 485-490. [Crossref]

28. Nesse W, Linde A, Abbas F, Spijkervet FK, Dijkstra PU, et al. (2009) Dose-response relationship between periodontal inflamed surface area and HbA1c in type 2 diabetics. J Clin Periodontol 36: 295-300. [Crossref]

29. Ayilavarapu S, Kantarci A, Hasturk H, Van Dyke TE (2014) IPLA2 mRNA expression by human neutrophils in type 2 diabetes and chronic periodontitis. J Int Acad Periodontol 16: 121-126. [Crossref]

30. Lim L, Tay FB, Sum CF, Thai AC (2007) Relationship between markers of metabolic control and inflammation on severity of periodontal disease in patients with diabetes mellitus. J Clin Periodontol 34:118-23. [Crossref]

31. Stewart JE, Wager KA, Friedlander AH, Zadeh HH (2001) The effect of periodontal treatment on glycemic control in patients with type 2 diabetes mellitus. $J$ Clin Periodontol 28: 306-310. [Crossref]

32. Herring ME, Shah SK (2006) Periodontal disease and control of diabetes mellitus. $J$ Am Osteopath Assoc 106: 416-421. [Crossref]

33. Teeuw WJ, Gerdes VE, Loos BG (2010) Effect of periodontal treatment on glycemic control of diabetic patients: a systematic review and meta-analysis. Diabetes Care 33: 421-427. [Crossref]

34. Mathews D (2005) The Two-Way Relationship Between Diabetes and Periodontal Disease. RCDSO Symposium, Oral Health: A Window To Systemic Disase 1-12.

35. O'Connell PA, Taba M, Nomizo A, Foss Freitas MC, Suaid FA, et al. (2008) Effects of periodontal therapy on glycemic control and inflammatory markers. J Periodontol 79 774-783. [Crossref]

36. American Diabetes Association (2015). Standard of Medical Care in Diabetes - 2015 Diabetes Care 38: S33-40.

37. Ismail-Beigi F, Moghissi E, Tiktin M, Hirsch IB, Inzucchi SE, et al. (2011) Individualizing glycemic targets in type 2 diabetes mellitus: implications of recent clinical trials. Ann Intern Med 154: 554-559. [Crossref]

38. Berkowitz SA, Atlas SJ, Grant RW, Wexler DJ (2014) Individualizing HbA1c targets for patients with diabetes: impact of an automated algorithm within a primary care network. Diabet Med 31: 839-846. [Crossref]

39. Centers for Disease Control and Prevention (2015) Centers for Disease Control and Prevention Diabetes Prevention Recognition Program.

40. Baldota KK, Leake JL (2004) A macroeconomic review of dentistry in Canada in the 1990s. J Can Dent Assoc 70: 604-609. [Crossref]

41. National Center for Health Statistics (2015) Health, United States, 2014: With Special Feature on Adults Aged 55-64:1-473.

42. Strauss S, Russell S, Wheeler A, Norman R, Borrell LN, et al. (2010) The dental office visit as a potential opportunity for diabetes screening: an analysis using NHANES 2003-2004 data. J Public Health Dent 70: 156-62. [Crossref]

43. National Diabetes Prevention Program (2016) CDC Prediabetes Screening Test. p. 2-3

44. Canadian Diabetes Association (2016) Screening for and Diagnosing Diabetes.

Copyright: $\odot 2016$ Sandhu HS. This is an open-access article distributed under the terms of the Creative Commons Attribution License, which permits unrestricted use, distribution, and reproduction in any medium, provided the original author and source are credited. 